\title{
FUNDAMENTAL CHARACTERISTICS OF SOLVENT-SOLUBLE POLYIMIDE RESIN AS A POLYMER FOR HYBRID APPLICATIONS
}

\author{
EIKI WATANABE \\ Department of Electrical Engineering, Faculty of Technology, Tokyo Metropolitan University, Tokyo, \\ Japan \\ KYOICHI KANOU \\ Reliability Section, Electronic Device Division, Electrotechnical Laboratory, Ibaraki Prefecture, Japan
}

TADASHI KUBOTA

Japan Technological Research and Development Laboratories, Co., Kokubunji-shi, Tokyo, Japan

\begin{abstract}
Polyimide resin of solvent-soluble type, which is called "X-resin" in short, was discovered lately. It is soluble in dimethylacetoamid (DMAc), and new extensive applications are expected .

Some physical, chemical and electrical characteristics are studied from the viewpoint of polymer material for hybrid application. Particularly comparison of the characteristics of X-resin specimens before and after long term exposure to humid and hot environments were made, remembering that electronic devices often operate under such conditions in Japan.

From the results obtained up to now, no conspicuous difference seems to exist between the characteristics of X-resin and those of the conventional (i.e., solvent-insoluble) resins, as published in various literature. It should be noted, however, that some unusual effects, i.e., the remarkable increase in surface resistivity $\sigma$, the evident decrease in $\tan \delta$, etc., were found in X-resin specimens after going through the above-mentioned damp-hot test. All those effects are contrary to the usual concepts of deterioration of polymer materials, but are rather advantageous for hybrid application. It is also worth noticing that silver migration into X-resin seems scarcely to occur.

Furthermore, new prospective uses of X-resin for printed wiring boards, packaging materials, binder for paste materials, etc., are investigated.
\end{abstract}

\section{INTRODUCTION}

Polyimide resins have outstanding physical, chemical and electrical characteristics combined with high thermal stability over a wide temperature range. Nevertheless their applications have been restricted to some particular uses in extreme environments, and they have scarcely been applied to hybrid or microelectronics devices. Manufacturers will encounter two serious problems when they attempt to use polyimide resin. One is the extreme expensiveness and the other is the awkwardness of forming and processing, since polyimides have been considered neither to melt nor to have any organic solvent. However, the former may be tolerated if the latter is solved, and extensive uses are developed. In consequence, the demands for polyimide resins rise steeply.

A new type of polyimide resin, which was called "X-resin" in short, found very recently. A remarkable feature of X-resin is that it has "specific" solvent-solubility similar to such usual linear polymers as polystyrene, etc., i.e., it can dissolve in a specific organic solvent even if it is once cured. Since it can be formed or processed far more easily than conventional polyimides, various new and extensive applications are looked forward to unless it has any fatal disadvantage in its properties.

Thus the physical, chemical and electrical characteristics of X-resin began to be studied as a possible polymer material for hybrid application. First of all, various characteristics of X-resin are compared 
with those of conventional polyimides. Damp-heat tests are also achieved for film specimens of X-resin, considering that in Japan electronic devices are often operated under humid conditions. In fact, moisture is the cause of some kinds of troubles in various electronic devices. Among these, a typical and serious one is metal migration into polymer materials.

\section{CHEMISTRY OF X-RESIN}

Conventional polyimides are formed typically by three stages as shown in Figure 1. Chemical reactions of $\mathrm{X}$-resin formation are considered to be substantially similar to those in Figure 1, except for a few modifications of conditions. Forming and processing of conventional polyimide resins are usually made for solventsoluble intermediate products at stage (II) (polyamic acid), because the final product at stage (III) (i.e., polyimide resin) has no solvent-solubility. On the other hand, $\mathrm{X}$-resin dissolves in a specific solvent. dimethylacetamide (DMAc), though it is considered to be equivalent to a final product at stage (III).

( I )<smiles>O=C1CC(=O)c2cc3c(cc21)C(=O)OC3=O</smiles>

$$
\text { Pyromellitic }
$$
dianhydride (PMDA)

$\Delta T$

$\left(25^{\circ} \mathrm{C}\right.$ to $\left.50^{\circ} \mathrm{C}\right)$

in a solvent such as dimethilacetamide (DMAC)

(II)

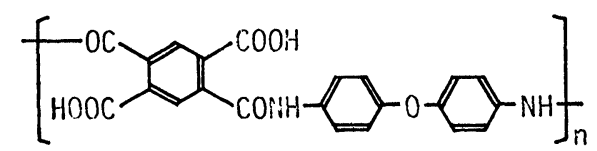

Polyamic acid(solvent-soluble)

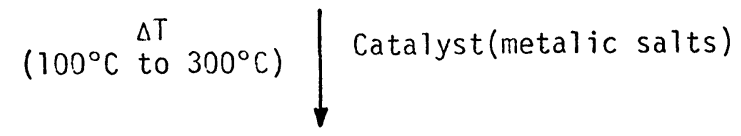

(III)<smiles>CC1(C)C(=O)c2cc3c(cc2C1=O)C(=O)N(c1ccc(Oc2ccc(N(C(C)(C)C)C(C)(C)C)cc2)cc1)C3=O</smiles>

Polyimide(solvent-insoluble)

FIGURE 1 Chemical reactions of polyimide formation.
From the results obtained by means of infra-red spectra studies, no conspicuous difference has been found between chemical structures of X-resin and conventional polyimide resin.

\section{SPECIMENS AND CONDITIONS FOR EVALUATION TESTS}

$\mathrm{X}$-resin specimens for various evaluation tests are prepared as follows: $\mathrm{X}$-resin powder dissolves in DMAc at a ratio of approximately 1 vs. 10 in weight to become a paste-like disposition. Then it is formed in sheets or films on a suitable flat plate. They are cured at $100^{\circ} \mathrm{C}$ for 30 minutes, and further heat-treated at $200^{\circ} \mathrm{C}$ for one hour for the purpose of sufficient volatilization of solvent. In addition, a sample heat-treated at $300^{\circ} \mathrm{C}$ is added for thermal analysis. Thickness of the specimens is between 100 and $200 \mu \mathrm{m}$.

Temperature and relative humidity for damp heat tests are usually determined respectively at $40 \pm 2{ }^{\circ} \mathrm{C}$ and $90-95 \%$ according to JIS (Japan Industrial Standards) C5023 "Damp Heat (Steady State) Testing Method for Electronic Components". The term of exposure can be selected from five steps between 48 and 1,000 hours. As for temperature, however, a somewhat severer condition, i.e., $70^{\circ} \mathrm{C}$, has been employed in this study, in order to facilitate the environmental deterioration of polymer specimens.

\section{TEST RESULTS AND EVALUATIONS}

TGA and DTA Thermogravimetric analysis (TGA) and differential thermal analysis (DTA) are achieved for three kinds of X-resin samples, and also for two kinds of conventional polyimide on the market for the purpose of comparative evaluation of the thermal resistance of X-resin. The specifications of those five

TABLE I

Specifications of polyimide samples for thermal analysis.

\begin{tabular}{lll}
\hline Sample & Trade name & Condition \\
\hline $\mathrm{A}$ & X-resin $^{\mathrm{a}}$ & $\begin{array}{l}\text { heat-treated at } 200^{\circ} \mathrm{C} \\
\text { heat-treated at } 300^{\circ} \mathrm{C}\end{array}$ \\
$\mathrm{B}$ & powder sample (before cured) \\
$\mathrm{C}$ & Kapton $^{\mathrm{b}}$ & heat-treated at $300^{\circ} \mathrm{C}$ \\
$\mathrm{D}$ & Torayneece $^{\mathrm{c}}$ & \\
$\mathrm{E}$ & \multicolumn{2}{l}{${ }^{2}$}
\end{tabular}


kinds of samples (sample A-E) are put together in Table I. The resultant TGA and DTA curves for $\mathrm{X}$-resins are shown in Figure 2, and those for conventional polyimides are shown in Figure 3. From TGA curves in Figure 2, it is observed that for sample $\mathrm{A}$ and $\mathrm{B}$ the first apparent decreases in weight begin from the temperatures a little over 200 and $300^{\circ} \mathrm{C}$ respectively. Note that those temperatures roughly coincide with those of heat treatments for each sample (cf. Table I). Moreover, from DTA curves in Figure 2, it is found that the above-mentioned decreases in weight are accompanied with endothermic chemical processes. The slight decrease in weight is also observed in sample $\mathrm{C}$ at a temperature as low as less than $100^{\circ} \mathrm{C}$, and is surely due to the desorption of gases absorbed on the surfaces of powder particles of X-resin sample. As for the conventional polyimide sample D and $\mathrm{E}$, neither a decrease in weight nor a chemical reaction is observed up to as high as near $500^{\circ} \mathrm{C}$, as shown on TGA and DTA curves in Figure 3. Thus the first decreases in weight of samples A and B should be caused by volatilization of residual solvent.

It is obvious that for all X-resin samples $(\mathrm{A}-\mathrm{C}$ ) the second abrupt decreases in weight begin from the coincident temperature, i.e., about $450^{\circ} \mathrm{C}$, as shown in
TGA curves in Figure 2. Those second decreases are all accompanied with somewhat complicated exothermic and/or endothermic reactions, as also shown in DTA curves in Figure 2. Thus those reactions are considered to correspond to thermal crackings of X-resin.

In consequence the thermal resistance of $\mathrm{X}$-resin is a little lower than that of conventional polyimides, but it can be improved remarkably by means of heat treatment at a relatively high temperature so that the residual solvent volatilizes completely.

\section{Electrical Characteristics $\mathrm{DC}$ and AC measurements} were made to obtain fundamental electrical characteristics of $\mathrm{X}$-resin. The resultant values for sample A are shown in Table II, together with those of conventional polyimides and, for ready comparison, some other resins which are often used in hybrid devices. Note that frequencies for AC measurements are different among various specimens.

The insulation resistance of X-resin has no substantial difference from conventional polyimides, and is roughly equal to or rather higher than those of epoxy resins. Taking the difference in measuring frequency into consideration, $\tan \delta$ of X-resin does not seem to be so large.

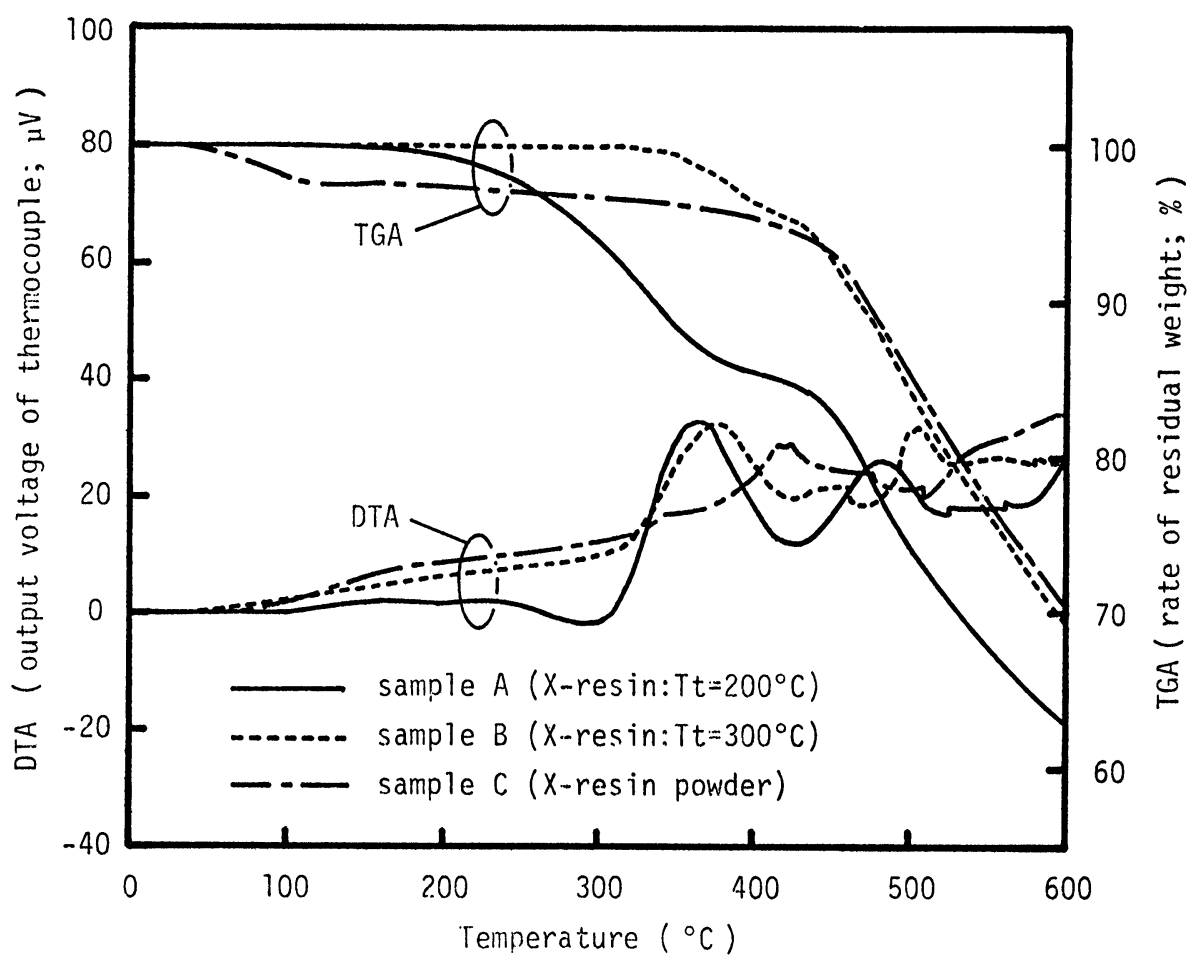

FIGURE 2 Results of TGA and DTA for X-resin samples. 


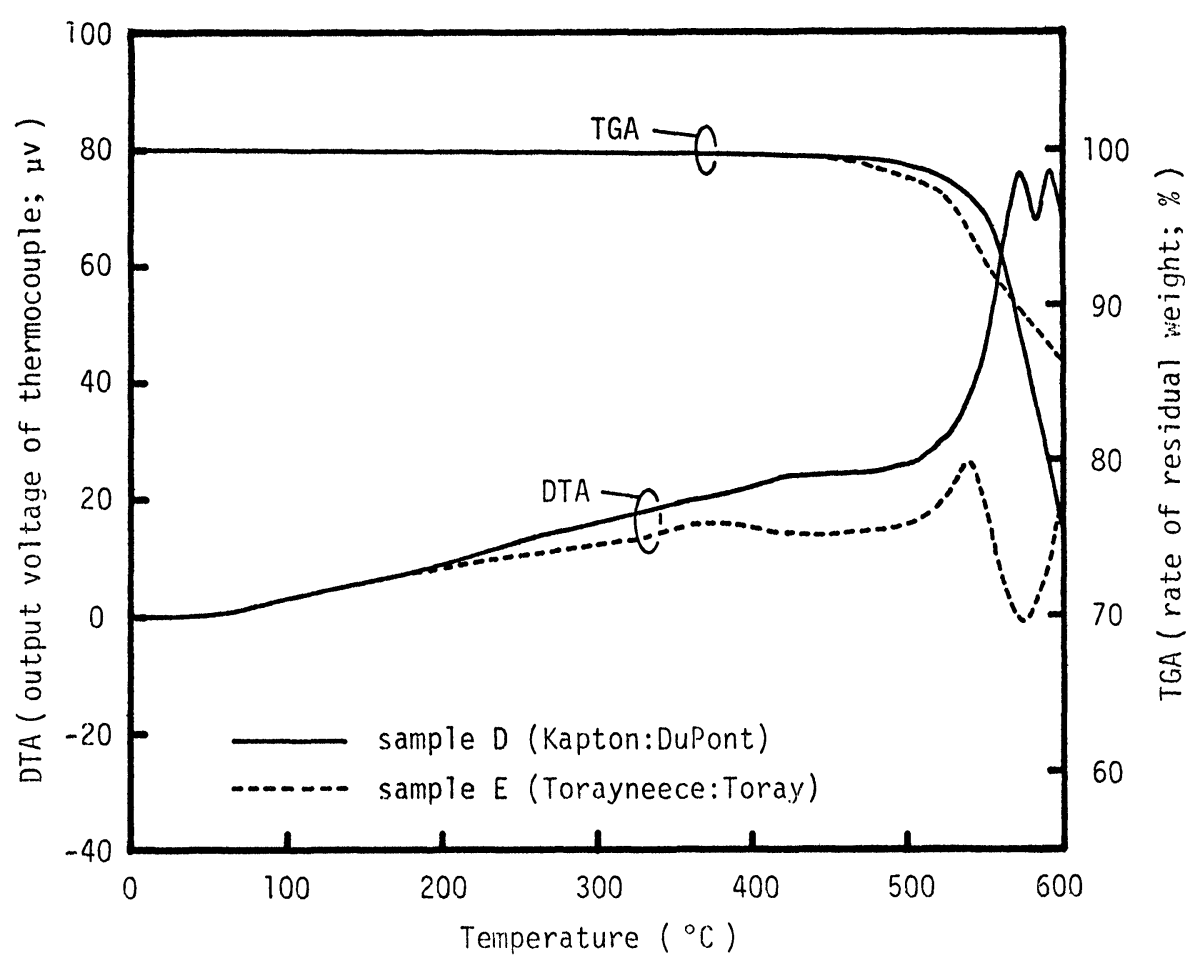

FIGURE 3 Results of TGA and DTA for conventional polyimides

TABLE II

Fundamental electrical characteristics

\begin{tabular}{lllll}
\hline Polymer & $\rho(\Omega \cdot \mathrm{cm})$ & $\sigma(\Omega)$ & $\varepsilon^{\prime}$ & $\tan \delta\left(\times 10^{-4}\right)$ \\
\hline X-resin (sample A) & $10^{16}-10^{17}$ & $10^{15}$ & $3.9(10 \mathrm{MHz})$ & $370(10 \mathrm{MHz})$ \\
conventional & & & $3.0(60 \mathrm{HZ})$ & $10-50(60 \mathrm{~Hz})$ \\
polyimide (Kapton) & $10^{16}-10^{17}$ & $* * * *$ & $3.5(1 \mathrm{KHz})$ & $>30(1 \mathrm{KHz})$ \\
phenol resin & $10^{11}-10^{12}$ & $* * * *$ & $5-15$ & $50-500$ \\
epoxy resin & $10^{16}$ & $* * * *$ & $3.5-5$ & $100-800$ \\
\hline
\end{tabular}

TABLE III

Results of damp-heat tests for electrical characteristics

\begin{tabular}{|c|c|c|c|c|c|c|}
\hline \multirow{2}{*}{$\begin{array}{l}\text { Condition of } \\
\text { samples }\end{array}$} & \multirow{2}{*}{$\rho(\Omega \cdot \mathrm{cm})$} & \multirow{2}{*}{$\sigma(\Omega)$} & \multicolumn{2}{|l|}{$\varepsilon^{\prime}$} & \multicolumn{2}{|c|}{$\tan \delta\left(\times 10^{-4}\right)$} \\
\hline & & & $10 \mathrm{MHz}$ & $50 \mathrm{MHz}$ & $10 \mathrm{MHz}$ & $50 \mathrm{MHz}$ \\
\hline before exposure & $10^{16}-10^{17}$ & $10^{15}$ & 3.94 & 3.95 & 366 & 308 \\
\hline after exposure & $10^{16}-10^{17}$ & $10^{19}$ & 3.94 & 3.97 & 186 & 151 \\
\hline
\end{tabular}


The results of damp-heat tests for the electrical characteristics of X-resin are tabulated in Table III. There are few differences in volume resistivity $\rho$ and permittivity $\varepsilon^{\prime}$ between the values before and after the exposure to testing environment. On the other hand, surface resistivity $\sigma$ increases remarkably and, at the same time, dielectric loss tangent $\tan \delta$ decreases almost to a half, contrary to usual tendency on deteriorated polymer materials due to moisture absorption and/or heat. The mechanisms of those unusual phenomena are now under investigation.

\section{Moisture Absorption and Permeability Moisture} absorption isotherms of X-resin specimens before and after exposure to the environment for damp heat tests are shown in Figure 4, where typical values of moisture absorption coefficient of conventional polyimides and some other practical polymers quoted from literatures are dotted together.

Generally speaking, the moisture absorption coefficient of X-resin is nearly equivalent to that of conventional polyimides, and is not so small among other resins.

It can be observed also in Figure 4 that moisture absorption of X-resin increases fairly after exposure to the damp-heat test environment.

Moisture permeabilities of X-resin are shown in Figure 5 with regard to the thickness of specimen. The

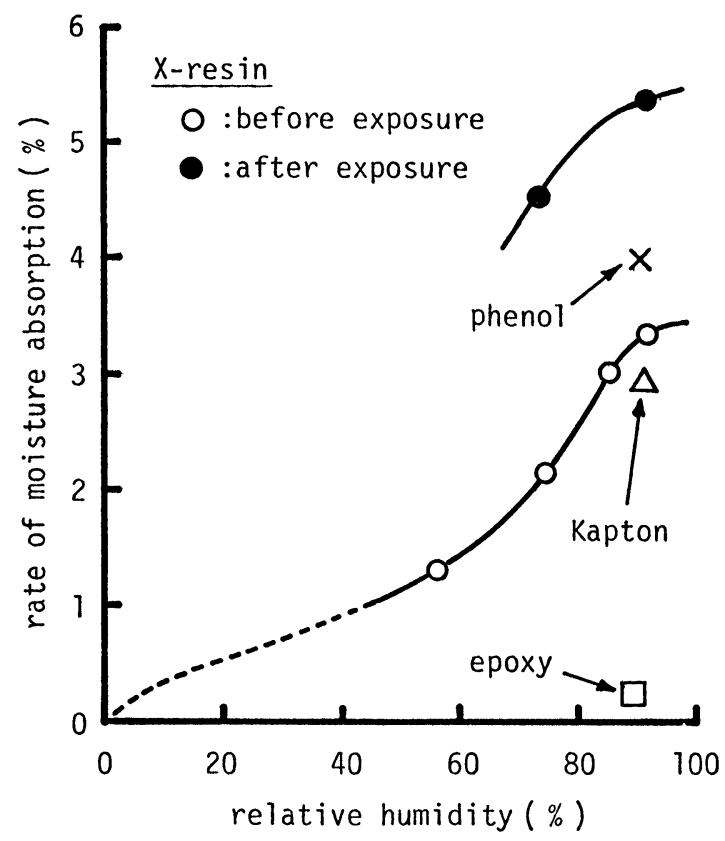

FIGURE 4 Moisture absorption isotherms of X-resin specimens. typical values for conventional polyimides and some other practical resins quoted from literature are also dotted together. Permeability of X-resin is a little larger than that of conventional polyimides. It also increases after exposure to the environment for damp-heat tests.

It is worth noticing again that unusual behaviours of $\sigma$ and $\tan \delta$ occur though moisture absorption and permeation of $\mathrm{X}$-resin are comparatively large.

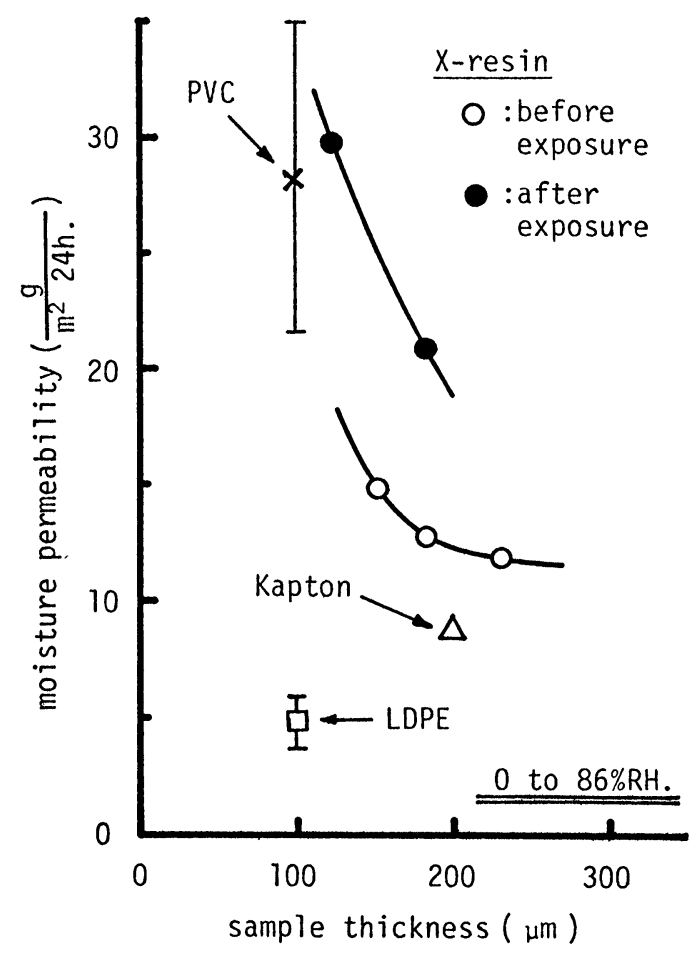

FIGURE 5 Moisture permeabilities of X-resin specimens.

Silver Migration Among other characteristics, metal migration is a matter of concern from viewpoint of hybrid applications, since it is often one of the serious problems in the humid climate such as Japan. Silver migration tests are being made for the samples of printed wiring board of X-resin. No conspicuous migration has been found until now though the tests are not finished yet.

\section{AVAILABILITY FOR HYBRID APPLICATIONS}

In view of the test results so far achieved, the characteristics of X-resin are considered not unfavourable compared with those of conventional 
polyimides and also some other resins. It is expected that in manufacturing processing the versatility of $\mathrm{X}$-resin owing to the solvent-solubility will more than make up for a few deficiencies, and will further open up new and extensive uses. Some instances of prospective applications are described below.

\subsection{Printed Wiring Board}

Printed wiring boards heretofore in use are mostly made of either phenol or epoxy resin reinforced with paper or glass cloth. They cannot be laminated as the polymers do not dissolve in any organic solvent after once being cured.

Supposing that printed wiring boards are made from $\mathrm{X}$-resin, they can be laminated to make multilayers after thick film devices are formed on each board, since surfaces of the boards are soluble in DMAc, and hence able to adhere tightly with each other. This means that a greater number of devices can be integrated within limited sizes.

Thermal stresses on printed wiring boards are necessarily exerted when they are going through the soldering processes for component-attachment, and often give rise to such troubles as warp of the board, exfoliation of conductor (metal) foil, etc. Thermal resistance of the boards is therefore one of the serious problems in order to ensure high reliability for hybrid devices.

Supposing again that $\mathrm{X}$-resin is utilized as a practical material for printed wiring boards, many kinds of thermal restrictions will be removed from componentattachment processes. Moreover, it may well be that new manufacturing methods can be developed since processing can be done at far higher temperature.

\subsection{Binder for Thick Film Materials}

$\mathrm{X}$-resin may well be utilized as binder of paste materials for thick film conductors, dielectrics and resistors. If the $\mathrm{X}$-resin paste is used in combination with the aforementioned $\mathrm{X}$-resin wiring boards, the fitness between them should be the best owing to their mutual solubility. Various heat treatments and processing will become possible with high accuracy in dimensions owing to high thermal stability and with almost the same thermal properties, e.g., thermal expansion coefficient, of both printed wiring boards and thick film devices upon them.

\subsection{Capacitor Dielectrics}

Lead wires of discrete components are often hooked to form semicircular portions as shown in Figure 6 for the

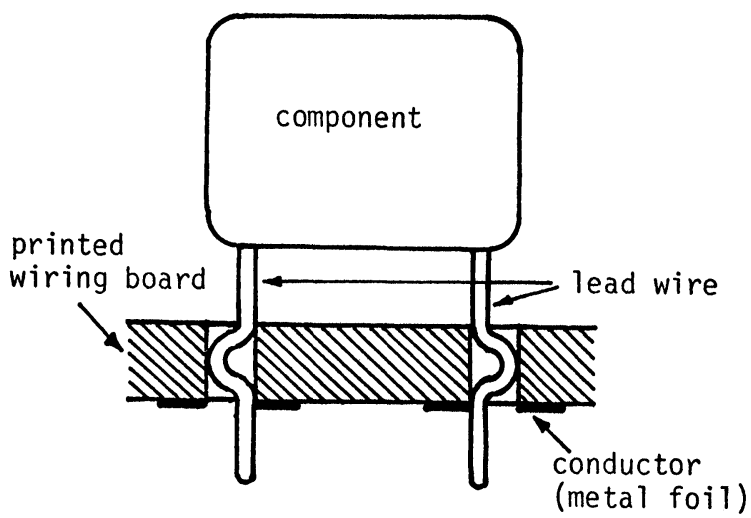

FIGURE 6 An example of hooked lead wires of component for the convenience of attachment processing.

purpose of making all components of uniform height and also preventing the lead wires from rattling or coming out during the attachment process. In this case, however, the lead wires should be made a little thicker so that the hooked portions cannot be distorted easily by mechanical forces. This means that heat transmission can occur easily through lead wires to the internal devices of electronic components. In fact, it has become one of the serious problems at present that capacitor dielectrics such as myler are often melted or deformed thermally at the connecting points of capacitor electrodes with lead wires during soldering. Thus higher thermal resistance is required for capacitor dielectrics.

$\mathrm{X}$-resin may be favourably used for such capacitor dielectrics as mentioned above.

\subsection{Packaging Materials}

Polymer materials have been widely used as moulding and coating materials for hybrid packaging. It goes without saying that X-resin can be used similarly. It may well be expected also that some new package constructions are developed making the most of the feature of X-resin i.e., the solvent solubility.

\subsection{Other Applications}

$\mathrm{X}$-resin may possibly have a capability of preclusive material for metal migration, though experimental supports are not sufficient yet.

\section{CONCLUSION}

The fundamental characteristics of X-resin are not synthetically inferior to those of conventional 
polyimides and other practical resins. The results of damp heat tests are noticeable, i.e., surface resistity $\sigma$ and dielectric loss tangent $\tan \delta$ change contrary to usual concepts of deterioration of polymers. These effects seem to be favourable for hybrid and microelectronic applications if they last a long period of time equal to the expected life spans of electronic devices.

The solvent-solubility will make it possible to develop various new methods of manufacturing processings and constructions of hybrid devices, in connection with their essential thermal resistance.
Polyimide resins have been used only for particular purposes mainly because of their extreme expense. It is expected, therefore, the new features of X-resin will develop new and extensive uses accompanied with new markets, and in consequence, bring about reduction of a cost in the near future.

\section{ACKNOWLEDGEMENTS}

The authors are indebted to Professor A. Kakimoto and Mr. $\mathrm{K}$. Ogawa who kindly undertook the measurements of dielectric characteristics, and to Professor Y. Awakuni for his helpful discussion. 

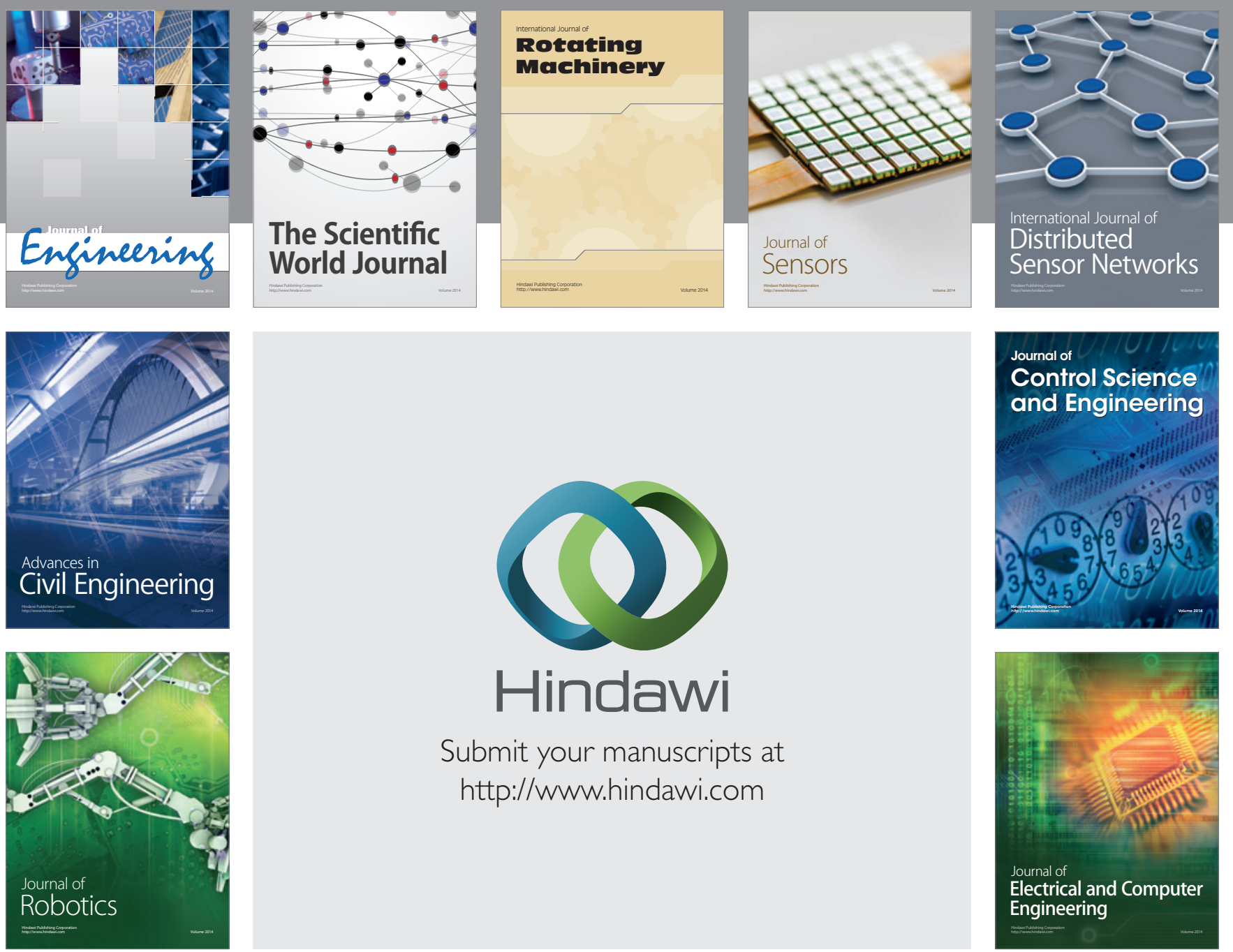

Submit your manuscripts at

http://www.hindawi.com
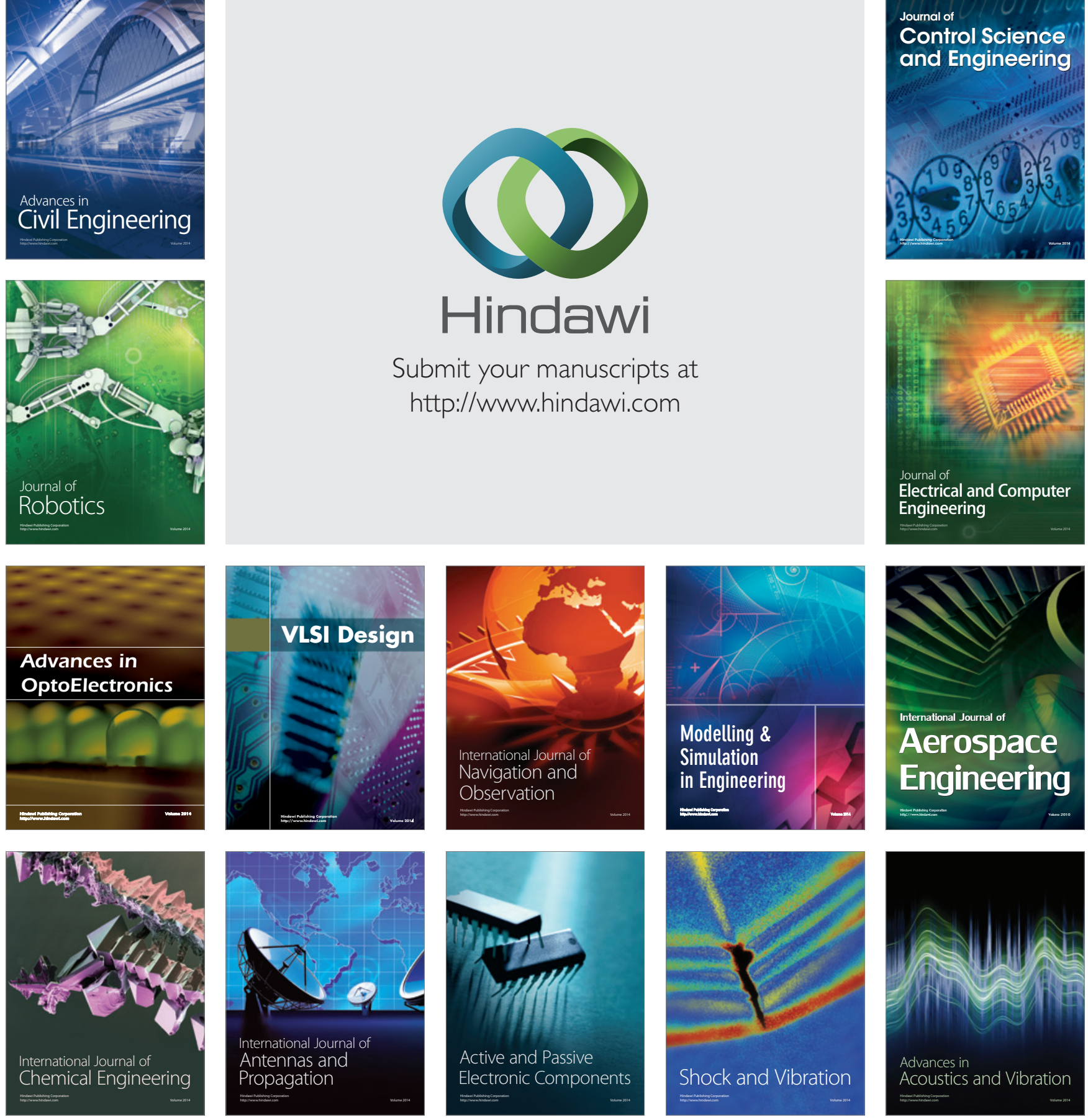